\title{
Linguagem esportiva italiana: o emprego de neologismos nas manchetes do portal Tuttosport
}

DOI: http://dx.doi.org/10.21165/el.v49i3.2505

\section{Thais Janeli ${ }^{1}$ \\ Vivian Orsi ${ }^{2}$}

\section{Resumo}

Este artigo pretende apontar algumas considerações sobre a linguagem esportiva italiana, tais como o uso de itens léxicos de língua estrangeira e a formação ou adoção de novas palavras, os neologismos lexicais. Para tanto, selecionamos quatro itens lexicais para serem explicados detalhadamente, extraídos de um corpus formado a partir de manchetes do portal esportivo italiano Tuttosport, a saber: Cristianomania, superfavorito, mask e Joya. Esta análise foi fundamentada na área de estudos da Lexicologia e da Neologia, com base na comparação de três fontes de consulta (dois dicionários monolíngues de italiano e uma enciclopédia da mesma língua), além de informações recuperadas no contexto de veiculação de manchetes.

Palavras-chave: linguagem esportiva; língua italiana; neologismos.

1 Universidade Estadual Paulista "Júlio de Mesquita Filho" (UNESP), São José do Rio Preto, São Paulo, Brasil; thy.bj@hotmail.com; https://orcid.org/0000-0002-2113-4636

2 Universidade Estadual Paulista "Júlio de Mesquita Filho" (UNESP), São José do Rio Preto, São Paulo, Brasil, vivian.orsi@unesp.br; https://orcid.org/0000-0002-7892-1091 


\title{
Italian sportive language: the usage of neologisms on headlines in the website Tuttosport
}

\begin{abstract}
This paper aims to point some considerations about the Italian sportive language, such as the usage of foreign lexical items and the formation or adoption of new words, the lexical neologisms. To do so, we selected four lexical items to be explained in detail, extracted from a corpus containing headlines from the Italian sports website Tuttosport, the following: Cristianomania, superfavorito, mask and Joya. This analysis was reasoned on the area of studies of Lexicology and of Neology, based on the comparison of three sources of consultation (two Italian monolingual dictionaries and an encyclopedia from the same language), in addition to information retrieved in the context of the publication of headlines.
\end{abstract}

Keywords: sportive language; Italian language; neologisms.

\section{Introdução}

Podemos levantar inúmeras discussões observando e analisando uma esfera do dia a dia que passa desapercebida por muitos, mas que é muito importante para outros: o esporte e a linguagem que se usa para tratar desse assunto.

Desde a criação da imprensa no século XV até os dias atuais, a maneira de contar e noticiar os fatos mudou, mas a vontade de documentar e contar o que acontece ao nosso redor é a mesma. No âmbito da linguagem esportiva falada, houve a transição das transmissões do rádio para as transmissões via televisão e no âmbito da linguagem esportiva escrita, houve a adição recente dos meios eletrônicos, nos quais o autor tem liberdade para corrigir uma informação mesmo depois que a notícia já foi veiculada, por exemplo.

As palavras, ou unidades lexicais, são elementos fundamentais para a comunicação e constituem o princípio essencial de todas as línguas do mundo. Existe uma ciência dedicada ao estudo delas, pois parece simples, mas há uma cadeia de relações complexa e intrínseca quando as analisamos. Para tanto, o trabalho que realizamos foi embasado pela Lexicologia, ciência que se ocupa do estudo do léxico. Aqui damos enfoque especial aos itens léxicos do universo da linguagem esportiva italiana - uma importante e relevante parte do léxico da língua italiana, englobando gírias e expressões rotineiras, assim como os neologismos criados a partir de um determinado aspecto da linguagem esportiva, usada por jornalistas e torcedores. 
Os esportes são, muitas vezes, pauta de inúmeras conversas em várias situações. Este campo lexical muito tem a contribuir para a língua geral - já que nele, como veremos, há inúmeras criações léxicas - utilizando-se dos meios de comunicação como jornais, revistas, programas de TV e, recentemente, os portais on-line e as redes sociais.

Podemos aprender muito ao observar a linguagem esportiva. Incorporamos palavras e expressões deste meio em nosso dia a dia. No português, por exemplo, usamos a expressão "bateu na trave", que transcendeu do meio futebolístico, em que significa, literalmente, uma bola que bate em uma trave, para o uso cotidiano ao querermos dizer "passou perto" ou "foi por pouco" que algo aconteceu.

A linguagem do esporte deve ser dinâmica e atraente para prender a atenção do leitor/ torcedor e os jornalistas esforçam-se para que suas notícias sejam objetivas. Uma das estratégias para tanto é explicitar, já nas manchetes, sobre quem vai se falar ou o que vai se noticiar, muitas vezes recorrendo a algumas inovações lexicais, como os neologismos, por exemplo. Tal fato chamou-nos a atenção para analisar as manchetes de um portal esportivo italiano e explorar as fascinantes características que a linguagem esportiva possui.

Assim, o léxico de um idioma, independente do momento histórico, não se amplia somente por meio do acervo já existente: podem ocorrer novas criações, os chamados neologismos, que resvalam no desenvolvimento do conjunto lexical de uma língua. Neologismo é, em síntese, uma nova unidade introduzida num idioma.

Esta observação e estudos sobre a linguagem esportiva italiana começaram como um projeto de iniciação cientifica, no ano de 2018 e evoluíram para uma dissertação de Mestrado, em andamento, neste momento. Esse assunto tem pouca difusão em língua portuguesa, o que faz com que esta reflexão seja uma modesta contribuição, pois, esperase que seus resultados sejam fonte para inspirar mais pesquisas e publicações sobre as particularidades da linguagem esportiva italiana e que possibilite aos nativos e falantes do português o contato com as descobertas feitas. Do corpus que foi selecionado (o qual detalhamos na seção "Procedimento metodológico"), selecionamos cinquenta itens léxicos para tecermos nossas observações e chegar às considerações sobre os neologismos das manchetes do portal Tuttosport. Desses cinquenta itens, selecionamos quatro para análise e comentário detalhado neste artigo.

\section{Fundamentação teórico-metodológica}

Abrimos a nossa fundamentação pautando sobre a grande área que norteou este trabalho, começamos por Orsi (2012, p. 164), que nos indica que a Lexicologia é "[...] considerada a ciência que estuda as unidades lexicais de uma ou várias línguas, seja no 
que tange ao significado ou ao significante, isto é, o léxico em todos os seus aspectos". Essa ciência embasou nosso estudo das particularidades da linguagem esportiva italiana, pois a análise dos itens léxicos retirados de determinado corpus nos permite apreender informações relevantes e observar, por exemplo, tendências de formação de novas palavras na língua ou, até mesmo, se há influência de itens léxicos de outras línguas naquela que se estuda.

Na Lexicologia, deixamos de lado o termo palavra ao nos referirmos aos signos linguísticos, ou unidades denominativas, a serem analisados dentro deste trabalho. Adotaremos a nomenclatura técnica para explorar o estudo das lexias das línguas, que constitui o principal foco da Lexicologia, portanto "item léxico" ou "unidade léxica" ou "lexia" foram e serão utilizadas aqui para referenciar os vocábulos da língua e tomadas como sinônimos para evitar a repetição em demasia.

Biderman (2001, p. 203) indica que a Lexicologia trata o léxico como um sistema aberto, em oposição a outros sistemas das línguas como a Fonologia e a Sintaxe, por exemplo, usadas para referenciar tanto o sistema quanto a ciência que o estuda. Dentro da Lexicologia, o léxico é considerado aberto porque passa por constante expansão e admite a criação e adição de novos itens lexicais que podem ser incorporados ao léxico das línguas.

Segundo a mesma autora:

As mudanças sociais e culturais acarretam alterações nos usos vocabulares; daí resulta que unidades ou setores completos do Léxico podem ser marginalizados, entrar em desuso e vir a desaparecer. Inversamente, porém, podem ser ressuscitados termos que voltam à circulação, geralmente com novas conotações. Enfim, novos vocábulos, ou novas significações de vocábulos já existentes, surgem para enriquecer o Léxico. (BIDERMAN, 2001, p. 179).

Sabe-se, portanto, que o léxico das línguas se expande, pois, as línguas são como organismos vivos e passam por constante mutação, em grande parte, impulsionada pelos próprios usuários/falantes, que se valem de sua criatividade e de seu conhecimento do sistema linguístico para dar nomes às coisas que são novas em sua realidade, bem como podem adotar lexias de outras línguas estrangeiras em suas interações no dia a dia. Algumas dessas lexias podem até mesmo figurar em dicionários, atestando que seu uso é recorrente e reconhecido, ao ganhar uma entrada no repositório de unidades lexicais de toda e qualquer língua.

Sendo assim, deve-se levar sempre em consideração o contexto no qual as notícias e manchetes esportivas são produzidas, pois estas têm como um dos principais objetivos 
captar a atenção do leitor e, por meio dos recursos linguísticos, tal como a formação de novas palavras ou até mesmo o uso de itens léxicos com nova significação. Como se viu na citação acima, os jornalistas que fazem uso da linguagem esportiva contribuem para enriquecimento e aumento do léxico geral da língua.

Alves (2002, p. 5, grifos da autora) explana, de maneira sucinta, os termos mais recorrentes da Neologia, ao postular que "Ao processo de criação lexical dá-se o nome de neologia. 0 elemento novo, a nova palavra, é denominado neologismo".

Carvalho (2006) indica que, historicamente, todas as lexias de uma língua já foram novidade um dia e somente a partir de um dado momento é que elas se tornaram parte comum do léxico. O fator social tem grande influência na criação de neologismos, pois, as novidades tecnológicas e atuais tendências em todos os âmbitos sociais (política, cultura, etc.) precisam ser "traduzidas" e registradas nos léxicos das línguas, afinal, Carvalho (2006, p. 192) afirma "A novidade das coisas ou dos conceitos precede a novidade dos meios de expressão", diz Boulanger (1979) [...]", assegurando, portanto, que a comunicação verbal entre os falantes seja contínua.

Justificamos novamente a relevância de pesquisas como a que propomos, que destacam a importância dos neologismos, pois, observamos que, muitas vezes, os jornalistas recorrem à formação de novos itens lexicais para buscar originalidade e expressividade nas notícias que eles reportam.

Murrmann e Surmaj (2015), ao analisarem as peculiaridades da linguagem jornalística, com base em artigos do cotidiano esportivo La Gazzetta dello Sport, apontam uma tendência de "expressividade" da linguagem esportiva, pois a função desta linguagem não é apenas descrever os eventos esportivos. Segundo as autoras, por meio dela, repleta de neoformações e entre outras características, procura-se criar efeitos precisos para atingir a audiência e criar efeitos no público leitor/consumidor das notícias. Há nas línguas a possibilidade de encontrarmos neologismos fonológicos (sem base em nenhuma unidade lexical já existente), sintáticos (combinação de elementos já existentes na língua) e semânticos (transformação semântica de uma unidade lexical); todos recursos que os usuários das línguas dispõem para a formação de novas palavras. Assim acontece também na esfera da linguagem esportiva, que precisa de lexias novas quando surge uma nova modalidade, diferente das demais, por exemplo.

A propósito dos empréstimos de outras línguas, apresentamos uma classificação em três grupos, proposta por Adamo (2010, p. 46), para determinar o caráter de cada tipo de empréstimo: em primeiro lugar, temos os estrangeirismos insubstituíveis, que são adotados por sua precisão e expressividade em denominar uma referência no mundo; em segundo lugar temos os estrangeirismos úteis, lexias que usufruem de certo prestígio entre os 
falantes, geralmente são lexias de circulação internacional; e, por fim, os estrangeirismos supérfluos, que possuem unidades léxicas de igual valor semântico na língua de origem. ${ }^{3}$

Não vamos nos ater aos inúmeros detalhes que a questão dos estrangeirismos desperta, porém, gostaríamos de reiterar nossa defesa à presença dos estrangeirismos não só na linguagem jornalística como também na linguagem geral, pois, cabe a eles denominarem, às vezes, conceitos e noções muitas vezes novos, alheios à determinada língua ou campo de conhecimento, como o exemplo fornecido por Adamo (2010, p. 67), podcasting, que designa uma modalidade de divulgação de conteúdo via áudio ou vídeo, unidade léxica que não se encontra traduzida ainda.

Não nos cabe, porém, legitimar ou descartar um neologismo ou estrangeirismo; apenas assinalamos a sua existência e quem determina se uma lexia entra ou não para o léxico de uma ou outra língua são os seus falantes, os usuários da língua, os leitores de jornais e páginas da web que têm contato direto com as lexias novas ou estrangeiras que, muitas vezes são selecionadas por jornalistas, pois é intenção destes causar ironia ou chamar a atenção de certa maneira; mas, que só passam ao uso corriqueiro e, consequentemente, até recebem registro nos dicionários, se os falantes adotam.

Observamos, ao realizar este trabalho, que na língua italiana há uma grande presença de empréstimos da língua inglesa (anglicismos), especialmente no campo esportivo e com abundante uso nas manchetes, para chamar a atenção dos leitores. A respeito dos itens léxicos de outras línguas, incorporados ao italiano, Bisetto (2003, p. 87) nos informa que seu uso é numeroso e se tornou praticamente "uma moda". A autora ainda afirma que algumas das lexias, especificamente de origem inglesa, inseridas no italiano (principalmente via imprensa), não apresentam tradução nem são indicadas entre aspas ou letra cursiva e que se encontram particularmente nos títulos (ou seja, as faixas do jornal que querem atrair a atenção).

\section{Procedimento metodológico}

Para levantar as considerações sobre a linguagem esportiva italiana, escolhemos o portal esportivo Tuttosport para recolher os itens léxicos a serem analisados e formar o nosso corpus. O cotidiano Tuttosport foi fundado em 1945, pelo jornalista Renato Casalbore, e é sediado na cidade de Turim (Piemonte).

3 A classificação dos estrangeirismos proposta pelo autor encontra-se sob os nomes originais de: extranjerismos insustituibles, extranjerismos útiles e extranjerismos supérfluos (ADAMO, 2010). A tradução no corpo do artigo foi de autoria nossa. 
De maneira geral, o enfoque do jornal e do portal é cobrir o dia a dia dos dois maiores clubes de futebol da cidade (Juventus e Torino) e noticiar sobre o principal campeonato de futebol do país (Série A), os demais campeonatos de futebol europeus, a Champions League e a Europa League (competições entre clubes de futebol europeus) e notícias das seleções italianas (masculina, feminina e de categorias de base). Destaca-se também a cobertura de outros esportes populares na Itália, como o basquete, o tênis, o ciclismo e o automobilismo. A publicação surgiu como concorrente a outros dois grandes jornais esportivos italianos, La Gazzetta dello Sport e /l Corriere dello Sport. Em 2008, o cotidiano ganhou um portal na internet, denominado Tuttosport - News su Calcio, Calciomercato, F7, Moto e altri sport, que é constantemente atualizado.

O procedimento metodológico adotado para a realização deste trabalho, em primeiro lugar, foi a formação do corpus. Este foi formado de dados recolhidos da página inicial ou homepage (somente manchetes, os títulos das notícias) do portal Tuttosport no período de 17 de dezembro de 2017 até 30 de setembro de 2018, que foram armazenados em planilhas. Neste período de pouco mais de nove meses, muitos foram os exemplos de potenciais neologismos e palavras de origem estrangeira encontrados no corpus formado.

Ressalta-se aqui que o trabalho realizado com este corpus não foi de cunho quantitativo, portanto, não nos interessou a quantidade total de itens lexicais recolhidos, e sim, apenas os itens que despertavam nosso interesse foram escolhidos para a análise.

Para tanto, a partir desse corpus, foram selecionados cinquenta itens lexicais para serem analisados. Os critérios de seleção foram os seguintes: unidades lexicais de língua estrangeira ou de origem italiana que pudessem ser potenciais neologismos, levando em conta nossa experiência de uso da língua e alguns fatores morfológicos, como a seleção de itens com plural em s, processo pouco produtivo em italiano, por exemplo, e lexias de origem estrangeira, alheias ao italiano.

Tomamos por base uma perspectiva sincrônica para formação do corpus utilizado nesta pesquisa, ou seja, não houve comparação com dados de outro período da história da linguagem esportiva italiana.

Os dados selecionados para análise foram organizados em quadros como o que apresentamos a seguir: 
Quadro 1. Ficha de dados montada para análise dos itens lexicais e expressões retirados do corpus

\begin{tabular}{|c|}
\hline DATA \\
\hline CONTEXTO/FRASE \\
\hline ITEM LÉXICO \\
\hline ANÁLISE \\
\hline
\end{tabular}

Fonte: Elaboração própria

"Data" corresponde à data na qual o item léxico foi encontrado no portal Tuttosport; "contexto/frase" é a manchete completa na qual o item léxico se encontra e "item léxico" é a parte em que se identifica qual item léxico será examinado em "análise". Na última linha, a análise foi feita com base na comparação de três fontes de consulta, a saber, os dicionários, em sua versão on-line, Sabatini Coletti (Dizionario Italiano - Vocabolario italiano - Corriere.it) e Grande Dizionario Hoepli Italiano; e a enciclopédia Treccani, também on-line, para checar se os itens recolhidos estavam ou não dicionarizados e presentes formalmente na língua italiana. A seção de análise também foi permeada com reflexões sobre neologismos/formação de palavras baseadas em Alves (2002) e Carvalho (2006), além de informações sobre contexto, quando julgou-se necessário recuperar a contextualização de um item léxico, levando em consideração a notícia por completo, disponível no portal "tuttosport.com".

\section{Análise e resultados}

Os resultados encontrados nos mostram que a maioria dos itens lexicais são empréstimos de cinco línguas que identificamos: vinte e seis itens de língua inglesa, cinco de língua espanhola, quatro de língua portuguesa, dois de língua francesa e um item de língua grega. Os sete itens restantes classificamos como formações neológicas pertencentes à língua italiana.

Notamos que a maioria das lexias recolhidas já figura nas fontes consultadas, podendo ser consideradas parte da língua em questão, se tomarmos como base o postulado de Alves (2002, p. 84): "Se bastante freqüente, o neologismo é inserido em obras lexicográficas e considerado parte integrante do sistema linguístico".

Optamos, então, por apresentar quatro itens lexicais com caráter neológico, a saber, Cristianomania, superfavorito, mask e Joya, para explaná-los.

O primeiro item léxico para análise foi Cristianomania. 
Quadro 2. Ficha de análise do item léxico Cristianomania

\begin{tabular}{|c|}
\hline \multicolumn{1}{|c|}{12 jul. 2018} \\
\hline JUVENTUS Juve, Cristianomania senza confini \\
\hline \multicolumn{1}{|c|}{ Cristianomania } \\
\hline $\begin{array}{l}\text { Item lexical de caráter neológico, é uma composição formada a partir de um nome próprio, } \\
\text { Cristiano, mais o sufixo grego -mania. O sentido pretendido pelo autor desta manchete é de } \\
\text { expressar que os torcedores da Juventus agora estão com "mania" (vício, obsessão) de Cristiano } \\
\text { Ronaldo, o novo contratado do time, pois compraram as camisas do craque português, até elas } \\
\text { se esgotarem das lojas oficiais da Juventus. Não aparece registrado nas fontes de consulta. }\end{array}$ \\
\hline
\end{tabular}

\section{Fonte: Elaboração própria}

O anúncio da chegada de Cristiano Ronaldo, jogador de futebol português, famoso por sua carreira em clubes como Manchester United e Real Madrid, para jogar no futebol italiano, na Juventus Football Club, aconteceu no dia 10 de julho de 2018 e chegou até mesmo a rivalizar manchetes com o evento mais importante do mundo do futebol que transcorreu na mesma época, a Copa do Mundo da Rússia (que aconteceu de 14 de junho a 15 de julho de 2018). Clara foi a intenção do jornalista em expressar a "mania" que Cristiano Ronaldo - considerado um astro e detentor de cinco prêmios da excelência individual do futebol, a Bola de Ouro - estava exercendo ao chegar para jogar no futebol italiano, tanto que a manchete mereceu uma criação neológica, para ajudar a expressar tamanha influência do português.

O segundo item que apresentamos para análise detalhada é superfavorito.

Quadro 3. Ficha de análise do item léxico superfavorito

\begin{tabular}{|c|}
\hline SCO jun. 2018 \\
\hline \multicolumn{1}{|c|}{ Superfavorito } \\
\hline $\begin{array}{l}\text { Este item lexical pode ser apontado como neologismo, pois, não aparece em nossas fontes de } \\
\text { consulta. "Superfavorito" é o resultado de uma composição por meio da junção do prefixo latino } \\
\text { super-, que indica superioridade e do adjetivo "favorito", que é o preferido, ou predileto a algo. }\end{array}$ \\
\hline
\end{tabular}

Fonte: Elaboração própria

Nesta manchete, o objetivo do autor foi demonstrar que, para as apostas (scommesse), o tenista sérvio Novak Djokovic, multicampeão de Grand Slams - os maiores torneios de tênis - era muito mais que o simples favorito a ganhar o confronto contra o tenista italiano Marco Cecchinato. Esse grande favoritismo, entretanto, não se confirmou no 
jogo, realizado um dia depois de esta manchete ser publicada, pois o italiano derrotou o sérvio por 3 sets a 1, em Roland Garros, segundo Grand Slam realizado naquele ano.

Adamo (2010) assinala que neologismos compostos são formados por meio da combinação de duas ou mais lexias preexistentes. Segundo o autor, a maioria dos neologismos por composição, encontrados em seu trabalho realizado com lexias oriundas da imprensa diária italiana, se forma a partir de bases comuns das línguas clássicas (latim e grego), às quais se juntam outros elementos para criação de novas unidades léxicas, como vimos em nossos dois exemplos acima.

O terceiro item léxico escolhido para análise foi mask:

Quadro 4. Ficha de análise do item léxico mask

\begin{tabular}{|l|}
\hline \multicolumn{1}{|c|}{02 fev. 2018} \\
\hline \multicolumn{1}{|c|}{ JUVENTUS Dybala in missione: voglia Champions e "mask" pronta } \\
\hline \multicolumn{1}{|c|}{ Mask } \\
\hline $\begin{array}{l}\text { Item léxico original da língua inglesa que significa "máscara", não aparece em ambos os } \\
\text { dicionários que usamos como fontes e aparece na enciclopédia Treccani com sentido totalmente } \\
\text { diferente do que o pretendido pela manchete, relacionado ao teatro. Neste contexto específico } \\
\text { mask se refere à comemoração que o jogador da Juventus, Paulo Dybala, faz quando marca } \\
\text { gols, imitando um gladiador mascarado. }\end{array}$ \\
\hline
\end{tabular}

Fonte: Elaboração própria

Como apontamos, mask ainda não aparece dicionarizado nas fontes que usamos para consulta. Um dos motivos plausíveis para que isto aconteça é porque o uso deste item léxico é consideravelmente novo na língua italiana e está ligado a uma característica particular de um determinado jogador, no caso, a comemoração após marcar gols do atacante argentino Paulo Dybala.

Esta comemoração, surgida em 2017, após o jogador marcar um gol e comemorá-lo levando uma das mãos ao rosto e cobrindo parte deste, imitando uma máscara, se tornou um viral da internet, com milhares de torcedores o imitando, como pode-se ver em vídeos e fotos postados pelo próprio jogador, em suas redes sociais ${ }^{4}$. Nesta rede surgiu a hashtag \#DybalaMask ("máscara do Dybala"), que, posteriormente, foi reduzida apenas a mask como vimos na manchete, em que o jornalista deseja nos informar, levando em

4 Vídeos e fotos de torcedores imitando a comemoração do jogador Paulo Dybala e postados sob a hashtag \#DybalaMask, podem ser encontrados na rede social Instagram, no perfil oficial do atleta, disponível em: https://www.instagram.com/paulodybala/?hl=pt-br. 
consideração o texto de toda a manchete, que Dybala estaria pronto para enfrentar uma missão na competição em questão (Champions League), na qual a Juventus, clube em que o atacante atua, precisava marcar gols para não ser eliminada e que, para tanto a mask, ou seja, sua comemoração após marcar gols e contribuir para as vitórias do clube, estaria pronta também.

Nota-se aqui uma tendência diferente da que foi apontado por Bisetto (2003, p. 87) anteriormente mencionada, de que os itens léxicos de origem inglesa, inseridos no italiano via imprensa, não apresentam tradução nem são indicados entre aspas ou com letra cursiva, pois mask, reproduzido precisamente como o encontramos na homepage do Tuttosport em 02 de fevereiro de 2018, aparece sinalizado entre aspas. A hipótese de que este item "soa" totalmente alheio à língua italiana e de que seu uso é novo e particular em determinado contexto, que apresentamos anteriormente, parece ser corroborada com o uso dessas aspas para indicar a comemoração do jogador.

O último item léxico a ser analisado é joya e apresentamos sua ficha a seguir:

Quadro 5. Ficha de análise do item léxico Joya

\begin{tabular}{|c|}
\hline \multicolumn{1}{|c|}{04 mar. 2018} \\
\hline \#JOYA SCUDETTO Juve, in coda Joya meravigliosa: Dybala batte la Lazio al 93' \\
\hline Joya \\
\hline $\begin{array}{l}\text { Não foram encontrados registros de verbetes ou uso em outros contextos deste item léxico na } \\
\text { língua italiana. Podemos, portanto, classificá-lo como um neologismo, pois a grafia é diferente } \\
\text { daquela do italiano, caracterizando um empréstimo da língua espanhola, pois esta é a origem } \\
\text { do item em questão; e não o encontramos dicionarizado, ainda, em nossas consultas aos } \\
\text { dicionários de língua italiana, nem com entrada na enciclopédia Treccani, caracterizando, assim, } \\
\text { uma novidade formal. Ademais, Joya é o apelido do jogador em questão nesta manchete, Paulo } \\
\text { Dybala, de origem argentina, que é chamado assim por torcedores e alguns veículos de imprensa. }\end{array}$ \\
\hline
\end{tabular}

Fonte: Elaboração própria

A língua espanhola foi a segunda língua estrangeira mais recorrente nos dados selecionados deste corpus (a primeira, como apresentado anteriormente, foi a língua inglesa) e trouxemos um exemplo do espanhol para análise. Apesar de ter a grafia parecida com a do italiano, muitos itens léxicos se destacam e acabam assumindo as características de neologismo por empréstimo, como é o caso do item léxico apresentado acima.

Novamente, a manchete se trata do jogador de futebol argentino, Paulo Dybala, aqui apontando seu apelido, ou seja, como ele é carinhosamente chamado por torcedores, 
fãs e alguns jornalistas, mais especificamente noticiando sobre um gol que ele marcou nesta data, que deu a vitória ao seu clube, a Juventus (ou Juve), nos últimos minutos do jogo, uma proeza. Neste caso, não conseguimos recuperar a origem do apelido, mas, supomos que seja pelo jogador produzir muitos dribles, belas jogadas e gols marcantes, tendo características similares a de uma joia, de valor e beleza inestimados.

O item léxico Joya aparece sem aspas, diferentemente do item anterior, mask. Voltamos ao nosso corpus e checamos a recorrência deste item léxico. Joya aparece em oito manchetes e em apenas duas delas veio entre aspas, seguindo a tendência do item do "Quadro 4". Por seis vezes, ou seja, na maioria, Joya aparece sem aspas ou marcação de itálico, como um item praticamente integrado à língua italiana, sem demonstração, da parte dos jornalistas, de um certo impedimento ou estranhamento em relação ao uso deste item léxico do espanhol. A grafia, por sua vez, é sempre em letra maiúscula, o que nos leva a supor que ela apareça grafada desta maneira por se tratar do apelido de Paulo Dybala, referido a um nome próprio.

Se este item léxico em questão vai ou não entrar para a língua formal italiana ou até mesmo figurar em seus dicionários não se sabe, pois D'Achille diz (2003, p. 66 apud SZEMBERSKA, 2010, p. 8) que muitos estrangeirismos não entram permanentemente para a língua, porque o uso deles decai depois de certo tempo, mais ou menos curto. Fato é que o uso de Joya não parece sofrer resistência pelos jornalistas, no corpus analisado, pois como se discutiu acima, seu uso foi, de certa forma, significativo.

\section{Considerações finais}

Em vias de conclusão, após análise de nossos dados, vemos que a principal maneira de inclusão de novos itens léxicos ao idioma objeto de estudo é por meio do empréstimo de língua estrangeira. Muitos são os motivos: manter a originalidade da modalidade (futebol, por exemplo, vem da Inglaterra e muitos itens léxicos relacionados ao futebol tem raiz inglesa ou são usados na língua de origem) ou captar a atenção do leitor, uma das estratégias das manchetes, para que o usuário da internet tenha seu interesse despertado e clique para ler a notícia toda.

Com a formação por composição (Cristianomania e superfavorito) ou empréstimo de línguas estrangeiras (mask e Joya), a língua italiana ganha cada vez mais itens e, com isso, seu conjunto léxico se expande, começando com o uso, muitas vezes informal, que tem início com torcedores ou em ambiente de redes sociais e pode vir a figurar na linguagem jornalística e, quem sabe, até mesmo na língua formal.

Notamos também, que, por vezes, o uso de determinado item léxico pode estar relacionado com a origem do atleta/jogador de que se trata na notícia, como vimos no exemplo do 
"Quadro 5", apresentado na seção anterior, com o emprego de Joya, item léxico espanhol, que é o apelido do jogador Paulo Dybala, que, por sua vez, tem origem Argentina, país da América Latina e que fala a língua espanhola. A participação em clubes italianos de jogadores de futebol oriundos de países de língua espanhola é muito grande e comum na Itália, principalmente depois da década de 1990, e tal fato ajuda a inserção cada vez maior de itens léxicos desta língua no italiano, pois há o favorecimento de troca intercultural e, consequentemente, de itens léxicos entre os falantes de ambas as línguas envolvidas.

Em suma, os neologismos da linguagem esportiva são abundantes e constituem a maior parte das particularidades pertinentes a este campo semântico, os quais, por sua vez e conforme o uso, podem passar a fazer parte da língua formal e da língua falada pelo povo, perfeitamente integrados.

Além disso, alguns neologismos lexicais surgidos na linguagem esportiva tornam-se, até mesmo, itens léxicos globalizados e de uso comum em inúmeras partes do mundo, transpondo assim as barreiras de idioma ou cultura, como os próprios esportes fazem.

\section{REFERÊNCIAS}

ADAMO, G. La neología italiana: panorama histórico, processos de formación y nuevas tendências em los neologismos de la prensa diária. In: ALVES, I. M. Neologia e neologismos em diferentes perspectivas. São Paulo: Paulistana, 2010. p. 35-61.

ALDO, G. Dizionario Italiano Online - Gratis ricerca di parole, significati e traduzioni - HOEPLI. it. Disponível em: http://www.grandidizionari.it/Dizionario_Italiano.aspx?idD=1. Acesso em: 19 jul. 2019.

ALVES, I. M. Neologismo. Criação lexical. 2. ed. São Paulo: Ática, 2002.

BIDERMAN, M. T. C. Teoria linguística. São Paulo: Martins Fontes, 2001.

BISETTO, A. Da formattare a calcio mercato: L'interferenza dell'inglese sull'italiano contemporaneo. In: CALLIMANI, A. V. S. (org.). Italiano e inglese a confronto. Firenze: Franco Cesati Editore, 2003. p. 87-99.

CARVALHO, N. M. A criação neológica. Revista Trama, v. 2, n. 4, p. 191-203, $2^{\circ}$ sem. 2006.

MURRMANN, J.; SURMAJ, P. La peculiarità del linguaggio giornalistico sportivo in base all'analisi degli articoli della Gazzetta dello Sport. Italica Wratislaviensia, 6, 2015, p. 197216. DOI: http://dx.doi.org/10.15804/IW.2015.06.12 
ORSI, V. Lexicologia: O que há por trás do estudo das palavras? In: GONÇALVES, A. V.; GÓIS, M. L. S. (org.). Ciências da linguagem: O fazer científico? Campinas: Mercado das Letras, 2012. p. 163-177.

SABATINI, F.; COLETTI, V. Dizionario Italiano - Vocabolario italiano - Corriere.it. Disponível em: http://dizionari.corriere.it/dizionario_italiano/index.shtml. Acesso em: 19 jul. 2019.

SZEMBERSKA, A. Forestierismi nel lessico calcistico italiano. 2010. Disponível em: http://romdoc.amu.edu.pl/Szemberska.pdf. Acesso em: 19 jul. 2019.

TRECCANI. Trecanni, il portale del sapere. Disponível em: http://www.treccani.it/. Acesso em: 19 jul. 2019.

TUTTOSPORT. Tuttosport - News su Calcio, Calciomercato, F1, Moto e altri sport. Disponível em: http://www.tuttosport.com/. Acesso em: 19 jul. 2019. 